\title{
Activity of Bimetallic Gold-Iron Catalysts in Adipic Acid Production by Direct Oxidation of Cyclohexene with Molecular Oxygen
}

\author{
Abdelkader Hakkoum ${ }^{1,2^{*}}$, Nawal Ameur ${ }^{1,3}$, Redouane Bachir ${ }^{1}$, Sumeya Bedrane ${ }^{1}$, Abderrahim Choukchou-Braham ${ }^{1}$ \\ ${ }^{1}$ Laboratory of Catalysis and Synthesis in Organic Chemistry, University of Tlemcen, BP 119 Imama, 13000 Tlemcen, Algeria \\ ${ }^{2}$ University of Hassiba Benbouali, Chlef, Algeria' \\ ${ }^{3}$ Oran's High School of Electrical Engineering and Energetic (ESGEE), BP 64 CH2 Achaba Hanifi USTO 31000 Oran, \\ Algeria
}

Corresponding Author Email: a.hakkoum@univ-chlef.dz

https://doi.org/10.18280/acsm.430504

Received: 20 July 2019

Accepted: 16 September 2019

\section{Keywords:}

oxidation, cyclohexene, gold, iron, doped material, catalysts

\begin{abstract}
This paper explores the properties of bimetallic catalysts based on gold and iron nanoparticles "Au-Fe/ $\mathrm{TiO}_{2}$ " and their application in the adipic acid production by direct oxidation of cyclohexene with molecular oxygen. The bimetallic materials were prepared with different amounts of gold and iron in two different methods: simultaneous deposition of $\mathrm{Au}$ and $\mathrm{Fe}$ using co-deposition precipitation with urea (Co-DPU), and deposition precipitation of gold followed by iron impregnation (DPU+IMP). The obtained catalysts were characterized by several techniques, such as XRD, RD/UV-Vis, ATR, ICP and BET. The properties of the catalysts prepared by different methods were compared, revealing that the metallic nanoparticles in the two methods differ in oxidation state, shape and size decrement. For cyclohexene oxidation by molecular oxygen, an important conversion of cyclohexene $(\approx 50 \%)$ was obtained just after $2 \mathrm{~h}$ in the case of $\mathrm{AuFeC}$ was observed. In terms of selectivity, all catalysts showed an excellent adipic acid production up to $90 \%$. The research establishes a green chemistry route from direct oxidation of cyclohexene to adipic acid using bimetallic catalyst in one-step reaction.
\end{abstract}

\section{INTRODUCTION}

Cyclohexene oxidation is one of the most used reactions in the manufacture of fine chemical products $[1,2]$, largely used in different applications and fields [3, 4]. Scheme 1 demonstrates the different products that can be obtained from cyclohexene oxidation [1-4]. The literature evoked the formation of more than seventy products and intermediates (gas, liquid and solid phases) from this reaction depending on the reaction conditions i.e. solvent, oxidant and the catalyst [2].

Nonetheless, the cyclohexene oxidation results in the primary stage of the reaction the formation of major products such as cyclohexene epoxide that can react with water to produce cyclohexan-1,2-diol, cyclohex-2-enone, cyclohex-2enol, cyclohexan-1-one and cyclohexan-1-ol (Scheme 2). In several cases and in the presence of an adequate quantity of oxidant, catalyst and solvent, the reaction can proceed to an advanced step of oxidation or what it is called "the autoxidation" is giving outcome in the formation of minor products such as acyclic-C5, acyclic-C6 and other products (Scheme 1) [2].

Adipic acid is one of the most important commercially available aliphatic diacarboxylic acids with a large industrial application in Nylon-6 and Nylon-66 manufacture, and intermediates for pharmaceuticals and insecticides [3, 4].

More active forms of oxygen donor were used, such as tbutyl hydroperoxide (TBHP) [5, 6] and $\mathrm{H}_{2} \mathrm{O}_{2}$ [6] although their disadvantages are to be expansive and harmful to the environment. The use of molecular oxygen in this kind of reaction as oxidant resulted in three important advantages, namely the facility to separate the catalyst after the reaction, a lower energy cost and a higher stability of the irreversible reaction over oxidation products, and the ability to represent the green options $[3,4]$.

Cai et al. [1] prepared supported gold on Manganese oxide octahedral molecular sieve (Au/OMS-2 and Au/La-OMS-2) prepared and used for liquid phase oxidation of cyclohexene with oxygen as an oxidant. The reaction was carried out in an autoclave at $80{ }^{\circ} \mathrm{C}$ without any solvent for 24 h. $0.24 \% \mathrm{Au} / \mathrm{La}-$ OMS-2 was found to be the most active catalyst for cyclohexene oxidation with a conversion of $48.0 \%$, and $86 \%$ of selectivity for $\Sigma \mathrm{C} 6$ (including cyclohexene oxide, 2cyclohexene-1-ol, 2-cyclohexene-1-one) was obtained [1]. The same group researchers tested the activity of the halloysite nanotubes supported gold in the cyclohexene oxidation with $\mathrm{O}_{2}$. The results showed that $0.37 \% \mathrm{Au} / \mathrm{HNTs}$ catalysts with gold particles $(<10 \mathrm{~nm})$ were highly active for the selective cyclohexene with a conversion in an order of $26 \%$ and a major selectivity to 2-cyclohexene-ol and 2-cyclohexene-one production [7]. They also used a bimetallic catalyst "Au$\mathrm{Ag} / \mathrm{C}$ " and evoked a conversion in an order of $27.6 \%$ and a high selectivity for $\sum \mathrm{C} 6$ (including cyclohexene oxide, 2cyclohexene-1-ol, 2-cyclohexene-1-one and cyclohexane-1,2diol) exceeding $88.9 \%$, especially the selectivity of cyclohexene-1,2-diol up to 47 at $80{ }^{\circ} \mathrm{C}$ and $0.4 \mathrm{MPa}$ for $12 \mathrm{~h}$ using TBHP as an initiator [7].

In our previous work, a study of the influence of gold nanoparticles oxidation state on cyclohexene oxidation by TBHP was carried out and we concluded that the reduced state 
of gold $\left(\mathrm{Au}^{0}\right)$ nanoparticles in $\mathrm{Au} / \mathrm{TiO}_{2}$ and $\mathrm{Au} / \mathrm{ZrO}_{2}$ catalysts showed better conversion than dried catalysts, and that the oxidation state of gold species $\left(\mathrm{Au}^{\delta+}\right)$ oriented the reaction to allylic oxidation products [6]. For the same reaction, we studied the catalytic activity of bimetallic catalyst "Au$\mathrm{Fe} / \mathrm{Al}_{2} \mathrm{O}_{3}$ ". In this case an important conversion was observed for monometallic catalysts (around $63 \%$ ) but for bimetallic catalysts the selectivity for cyclohexane oxide (epoxide) was improved by iron nanoparticles and a very important selectivity towards the formation of epoxide was achieved [5].

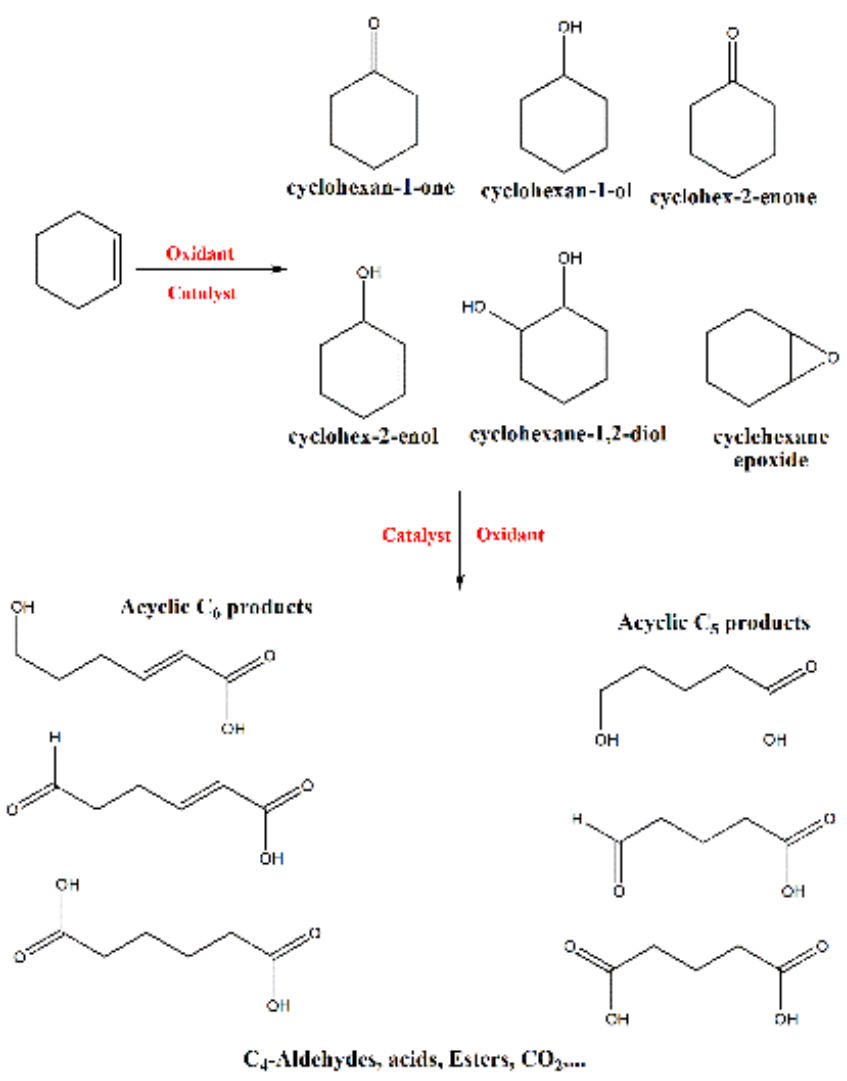

Scheme 1. Different product issues from cyclohexene oxidation

The present work is a continuation of the previous works of our team which aims at understanding the catalytic behavior of the different materials (especially nanocatalysts) in this kind of application and at the same time improving the yield of products with industrial value.

The aim of the present work is to study the catalytic activity of bimetallic catalysts in the cyclohexene oxidation using molecular oxygen as oxidant. Herein, two different ways to synthesize these catalysts were used:

i. Preparation in one-pot: a simultaneous deposition of $\mathrm{Au}$ and $\mathrm{Fe}$ on $\mathrm{TiO}_{2}$ surface using deposition precipitation with urea (Co-DPU).

ii. Preparation in two steps: a preparation of $\mathrm{Au} / \mathrm{TiO}_{2}$ using deposition precipitation with urea (DPU) followed by iron impregnation (DPU+IMP).

\section{EXPERIMENTAL SECTIONN}

\subsection{Preparation of $\mathrm{Au}-\mathrm{Fe} / \mathrm{TiO}_{2}$ in one-pot (Co-DPU)}

$\mathrm{TiO}_{2}$ (P25, Degussa) was used as a support oxide for all catalysts. So as formerly described in our previous work $[5,6]$, a suspension containing $1.98 \mathrm{~g}$ of Titania was heated at $80{ }^{\circ} \mathrm{C}$, then the $1.9 \mathrm{~g}$ of urea, $4 \mathrm{~mL}$ of gold and $13.4 \mathrm{~mL}$ of iron precursors (solutions at $10 \mathrm{~g} / \mathrm{L}$ of $\mathrm{HAuCl}_{4} .3 \mathrm{H}_{2} \mathrm{O}$ and $\left.\mathrm{Fe}\left(\mathrm{NO}_{3}\right)_{3} .9 \mathrm{H}_{2} \mathrm{O}\right)$ were added to the mixture and left under steering at the same temperature for $16 \mathrm{~h}$. After that, obtained solid was washed several times with distillated water to eliminate all unlike ions $\left(\mathrm{NO}_{3}{ }^{-}, \mathrm{Cl}^{-}\right)$, and was dried all night at $80^{\circ} \mathrm{C}$. Finally, the as-prepared catalyst was annealed under $\mathrm{H}_{2}$ $(10 \mathrm{cc} / \mathrm{min})$ at $200{ }^{\circ} \mathrm{C}(2 \% \mathrm{~min})$ for $4 \mathrm{~h}$.

\subsection{The deposition precipitation of gold followed by iron impregnation (DPU+IMP)}

Monometallic catalyst was prepared by deposition precipitation by urea (DPU) as described above (without iron) and in our previous works [5, 6]. Bimetallic catalyst was prepared by impregnation of iron nitrate on monometallic catalysts prepared previously. So, for a monometallic catalyst suspension $\left(\mathrm{Au} / \mathrm{TiO}_{2}\right), 13.4 \mathrm{~mL}$ of iron nitrate solution $(\mathrm{Fe}$ $\left.\left(\mathrm{NO}_{3}\right)_{3} .9 \mathrm{H}_{2} \mathrm{O}, 10 \mathrm{~g} / \mathrm{L}\right)$ was added in dropwice. This mixture was aged for $4 \mathrm{~h}$ at room temperature. Then, the solvent excess was evaporated at $100{ }^{\circ} \mathrm{C}$ for $24 \mathrm{~h}$; and finally the obtained solid was annealed under $\mathrm{H}_{2}$ at $200{ }^{\circ} \mathrm{C}$ for $4 \mathrm{~h}$.

\subsection{Characterization techniques}

The chemical composition of the samples was determined by inductively coupled plasma emission spectroscopy (ICP) using a Varian ICP OES. The crystalline phases of catalysts were identified by X-ray diffractometer (Shimadzu, XRD$6000, \mathrm{CuK} \alpha$ radiation). The BET surface area was determined from $\mathrm{N}_{2}$ adsorption-desorption isotherms at $77 \mathrm{~K}$ using a Quantachrom NOVA 1000 instrument. Before analysis, the catalysts were previously out gazed at $523 \mathrm{~K}$ for $2 \mathrm{~h} 30 \mathrm{~min}$. The RD/UV-visible spectra $(200-800 \mathrm{~nm})$ of catalysts were realized on an UV/Vis spectrometer Perkin Elmer with integration sphere. The baseline was recorded using $\mathrm{MgO}$ as a reference. Finally, the FTIR spectra of the materials were recorded using an Agilent Technology Cary 60 series FTIR spectrometer, with ATR accessories, and a measuring range of $4000-500 \mathrm{~cm}^{-1}$.

\subsection{Cyclohexene oxidation}

As was described in our previous works [3, 4]. The catalytic test for cyclohexene oxidation by molecular oxygen was realized in a Parr 5500 series compact reactor (Capacity $=0.14$ $\mathrm{L}$, pressure maximum 200 bars) related to the Parr control of temperature and stirring. Typically, $4.5 \mathrm{~mL}$ of cyclohexene, 75 $\mathrm{mL}$ of $\mathrm{n}$-heptane and $0.1 \mathrm{~g}$ of catalyst were placed into a reactor. The reactor was closed and purged several times to eliminate all air molecules. The temperature was then heated to $80^{\circ} \mathrm{C}$. After that, the molecular oxygen was sent ( $\mathrm{P}=6$ bars) under stirring and the reaction was started and maintained under stirring for $24 \mathrm{~h}$. The samples were analyzed by gas chromatography (GC and GC-SM). The cyclohexene conversion and the selectivity towards different products were calculated using the following formula (Eq. 1 and Eq. 2):

$$
\begin{aligned}
& \text { Conversion(\%) }=100 * \frac{\mathrm{C}_{0}-\mathrm{C}_{\mathrm{f}}}{\mathrm{C}_{0}} \\
& \text { Selectivity(\%) }=100 * \frac{\mathrm{C}_{\mathrm{i}}}{\mathrm{C}_{0}-\mathrm{C}_{\mathrm{f}}}
\end{aligned}
$$




\section{RESULTS AND DISCUSSIONS}

Table 1 shows the results of ICP and BET characterizations. Monometallic catalysts (AuTi and FeTi) were prepared by DPU with the aim to compare their proprieties with bimetallic materials. As a conclusion, DPU allows depositing a comparative and a good amount of $\mathrm{Au}$ or $\mathrm{Fe}$ on the $\mathrm{TiO}_{2}$ surface.

Regarding the BET surface of all catalysts, it can be concluded that the metallization of $\mathrm{TiO}_{2}$ leads to a little improvement of the surface area which can be related to the participation of metallic species on the total surface.

For bimetallic catalysts, a very close amount of gold and iron species were present in the materials. This indicates that the preparation method does not affect the Au or Fe loading.

Table 1. ICP and BET analysis of prepared materials

\begin{tabular}{cllc}
\hline Catalysts & \multicolumn{2}{c}{ Designation } & S $_{\text {BET }}\left(\mathbf{m}^{\mathbf{2}} \mathbf{g}^{\mathbf{1}}\right)$ \\
\hline $\mathrm{TiO}_{2}(\mathrm{P} 25, \mathrm{Degussa})$ & $\mathrm{Ti}$ & 41 & 41 \\
$1.7 \% \mathrm{Au} / \mathrm{TiO}_{2}$ & $\mathrm{AuTi}$ & 52 & 52 \\
$1.6 \% \mathrm{Fe} / \mathrm{TiO}_{2}$ & $\mathrm{FeTi}$ & 50 & 50 \\
$0.63 \% \mathrm{Au}-0.8 \% \mathrm{Fe} / \mathrm{TiO}_{2}$ & $\mathrm{AuFeI}$ & 66 & 66 \\
$0.68 \% \mathrm{Au}-0.91 \% \mathrm{Fe} / \mathrm{TiO}_{2}$ & $\mathrm{AuFeC}$ & 61 & 61 \\
\hline
\end{tabular}

XRD patterns of the prepared catalysts are shown in Figure 1. It can be noticed that titania presents peaks characteristic of the anatase and rutile phases (JCPDS Files No.: Anatase: $21-$ 1272 and Rutile: 21-1276). For monometallic AuTi catalyst, gold nanoparticles appear at $2 \theta=38^{\circ}, 44.5^{\circ}, 64^{\circ}$ and $78^{\circ}$ related to the faces (111), (200), (220) and (311), respectively (JCPDS file: 04-0784). In AuFeC, gold nanoparticles reveal a very small peak at $44.5^{\circ}$. In contrary, iron particles did not show any peak in all doped-catalysts. This may be related to their low amount and probably the best distribution of the Fe particles on the support surface.

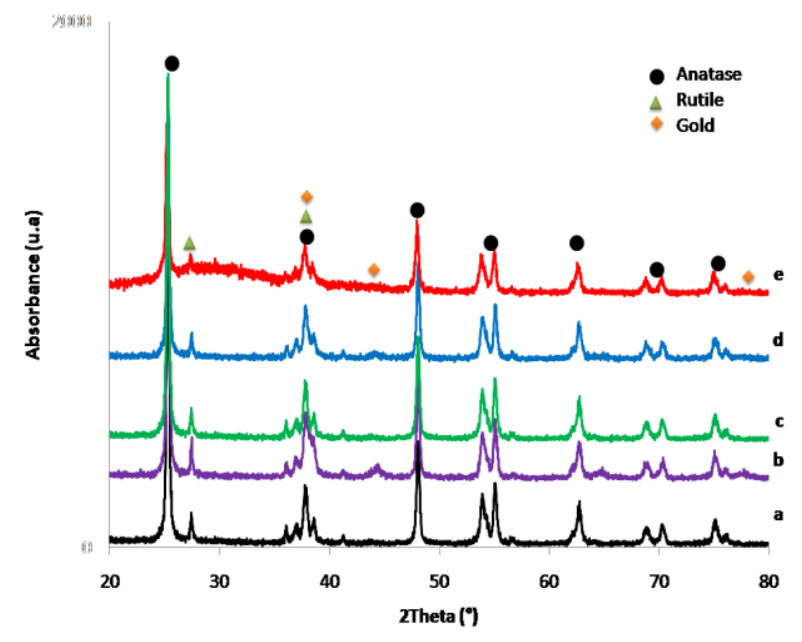

Figure 1. XDR patterns of (a) Ti, (b) AuTi, (c) FeTi, (d) $\mathrm{AuFeC}$ and (e) AuFeI

Characterization by RD/UV-Vis is an important method to determine the proprieties of the different species on catalysts. Herein, we work with three different metals: Ti, Fe and Au. This method can provide several details about the phase nature, the oxidation state, the shape and the size of the final particles $[3,4,6]$.

The deconvolution of Ti spectrum (Figure. 2) shows four bands centered at: 238, 277, 314 and $352 \mathrm{~nm}$; close with those founded in the literature $[3,4,6]$. The first one can be generated by the $\mathrm{Ti}^{4+}$ cations in tetrahedrical environment, and is provided by the electronic transfer between $\mathrm{Ti}^{4+}$ and oxygenated ligands such as: $\mathrm{O}-\mathrm{H}, \mathrm{O}-\mathrm{Ti}$ or $\mathrm{H}_{2} \mathrm{O}$. The band around $277 \mathrm{~nm}$ may be due to the $\mathrm{Ti}^{4+}$ in the octahedrical environment. At 314 and $352 \mathrm{~nm}$ appears the absorption of rutile and anatase phases, respectively. The presence of these bands confirms the composition of employed P25, which is composed of anatase and rutile phases (80 and $20 \%$, respectively).

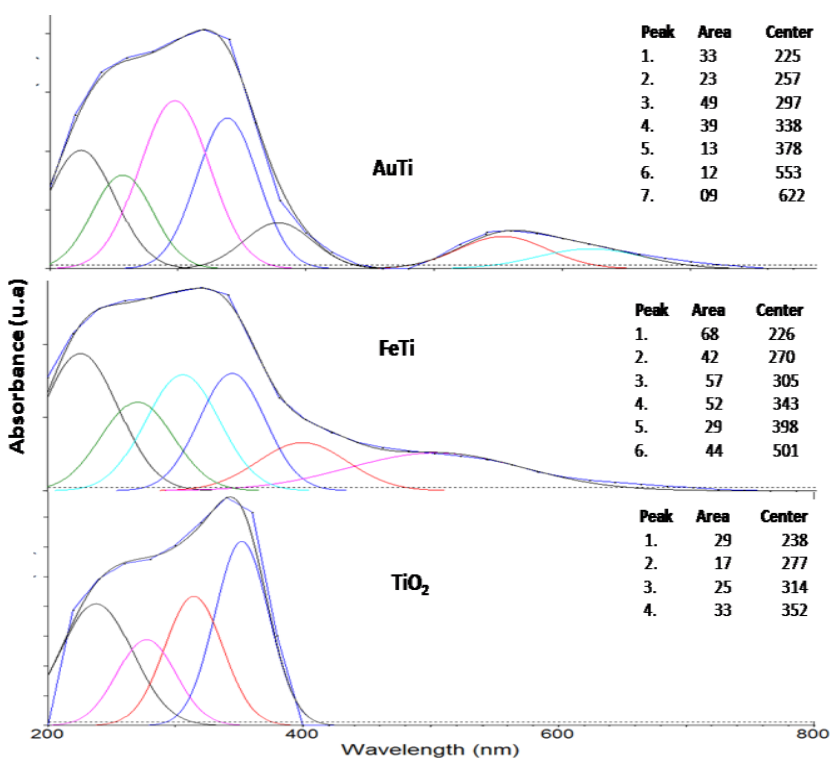

Figure 2. RD/UV-Vis Spectra of the characterization of monometallic catalysts

For the monometallic catalysts (AuTi and FeTi), we confirm the presence of four bands in the UV range related to the support with a slow shift (Figure 2). Also, an enhancement of the absorption in the visible region $\sim 400-800 \mathrm{~nm}$ is observed which can be attributed to the Au and Fe particles.

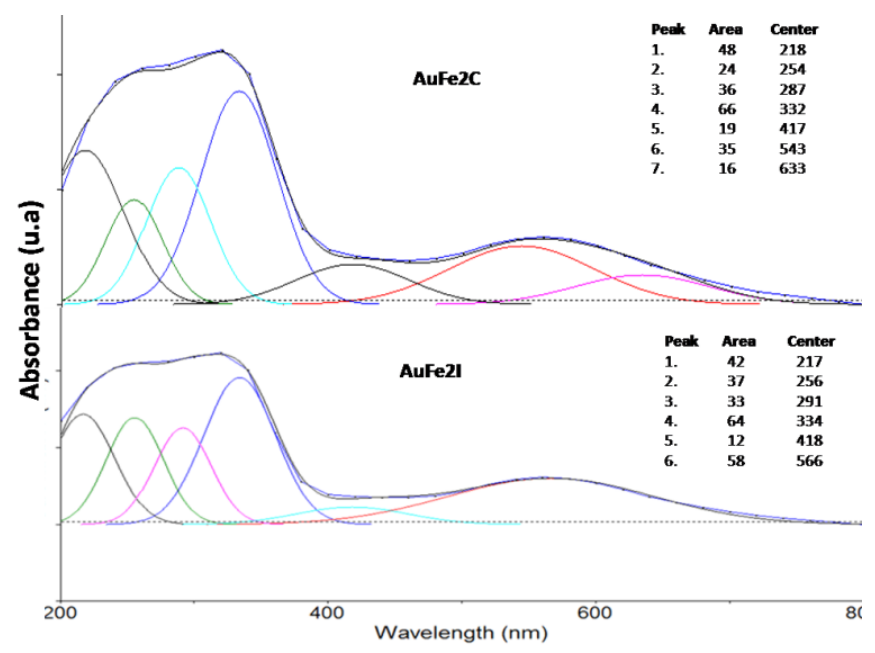

Figure 3. Deconvolved RD/UV-Vis spectra of bimetallic catalysts

AuTi material shows three new bands centered at 378, 553 and $622 \mathrm{~nm}$. The first one may be related to the gold cluster in oxidized state " $\mathrm{Au}_{\mathrm{n}}{ }^{\mathrm{\delta}}$ " [8], whereas the second and the third ones are regenerated by the resonance plasmon band of reduced gold nanoparticles " $\mathrm{Au}$ " " with non-spherical shape $[5$, 
6]. Hence, where the gold nanoparticles are non-spherical they present two modes of vibrations; the first one about $550 \mathrm{~nm}$ related to the longitudinal vibration and the second at $622 \mathrm{~nm}$ related to the transversal vibration. These two vibration modes are the origin of the resonance plasmon band with two maxima at $550 \mathrm{~nm}$ and $622 \mathrm{~nm}$. In addition, this band is influenced by several parameters, such as the environment of the gold nanoparticles, their size, shape and concentration $[5,6,8]$.

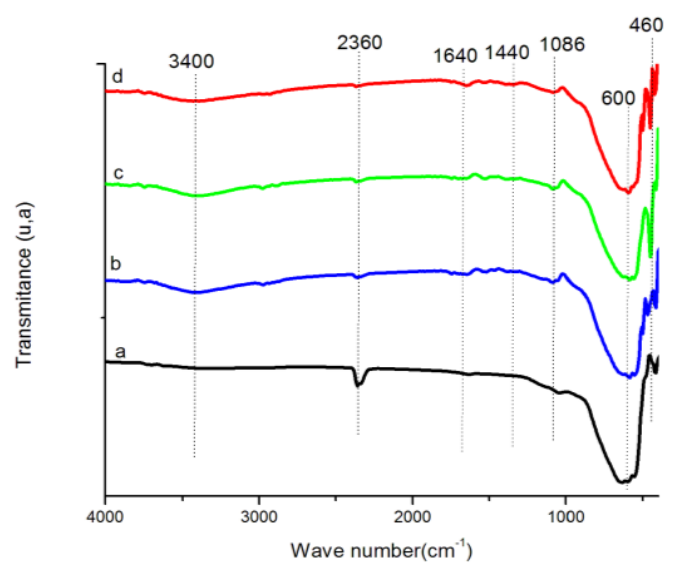

Figure 4. FTIR spectra of Ti (a), FeTi (b), AuFeC and AuFeI

However, the choice of this low reduction temperature has been made to ovoid the centering of the metallic species especially in the case of bimetallic catalysts. In this case, R. Zanella et al. [9] were found that the increase of the annealing temperature leading to the low increase of gold nanoparticles' size. So, for supported $\mathrm{Au} / \mathrm{TiO}_{2}$ prepared by DPU, they obtained 1.4, 1.6, 1.8 and $2.3 \mathrm{~nm}( \pm 0.5 \mathrm{~nm})$ for the treatment temperature in $\mathrm{H} 2$ of $200,300,400$ and $500{ }^{\circ} \mathrm{C}$, respectively. This indicates that the particles are stabilized by the support oxide. They were also found after RD/UV-Vis and EXAFS characterizations at $200{ }^{\circ} \mathrm{C}$, that most of gold nanoparticles were typically in their metallic state, i.e. $\mathrm{Au}^{0}[10]$.

Monometallic catalyst based on iron particles (FeTi) shows two new bands at 398 and $501 \mathrm{~nm}$ which can be related to $\alpha$ $\mathrm{Fe}_{2} \mathrm{O}_{3}$ species and influenced by the iron particles' size. So, the first one around $400 \mathrm{~nm}$ may be related to oligomeric clusters and the second to the large particles of $\alpha-\mathrm{Fe}_{2} \mathrm{O}_{3}$ (transition d-d) [3, 4]. Figure 3 shows RD/UV-Vis of bimetallic catalysts. Titania presents an important absorption in the UV zone; so that in the presence of metals ( $\mathrm{Au}$ and $\mathrm{Fe}$ ) it changes its intensity and shows a blue shift which can be related to the interaction between metal and support [11]. In addition, the presence of metallic particles distributed on $\mathrm{TiO}_{2}$ surface can also make the contact between UV irradiation of the spectrometer and $\mathrm{TiO}_{2}$ surface difficult, consequently; affecting the intensity of this region. For AuFeC, the gold nanoparticles appear with non-spherical shape confirmed by the presence of two maxima of the resonance plasmon band at 543 and $633 \mathrm{~nm}[12,13]$. In AuFeI, they show a spherical shape established by the appearance of a unique maximum of the resonance plasmon band at $566 \mathrm{~nm}$. The bands at 417 and $418 \mathrm{~nm}$ may be attributed to the $\alpha-\mathrm{Fe}_{2} \mathrm{O}_{3}$ particles in the bimetallic catalysts $[3,4]$.

Figure 4 presents the Fourier Transform Infrared (FTIR) spectra of prepared materials. It is noticed that AuTi does not show any difference from the spectra of $\mathrm{TiO}_{2}$. For this reason, its spectrum is not presented. The IR spectrum of all catalysts reveals the presence of a main band centered at $600 \mathrm{~cm}^{-1}$, which is attributed to the stretching vibrations of the Ti-O-Ti group of the anatase phase. However, the band at $460 \mathrm{~cm}^{-1}$ may be related to the rutile phase. The broad peaks at 3400 and $1440-1640 \mathrm{~cm}^{-1}$ are assigned to water stretches and bends, respectively $[14,15]$. The Fe-O-Ti band appears at $1086 \mathrm{~cm}-1$ which may be related to the stretching vibration mode. Finally, the $2360 \mathrm{~cm}^{-1}$ may be attributed to the $\mathrm{CO}_{2}$ molecules confined in the pores $[16,17,3,4]$.

\subsection{Cyclohexene oxidation by molecular oxygen:}

Cyclohexene oxidation leads to the formation of different products as shown in Scheme 1. In our case, molecular oxygen is used as an oxidant (6 bars) and n-heptane as solvent $(75 \mathrm{~mL})$. However, at $80^{\circ} \mathrm{C}$ one would expect that cyclohexene was in the liquid phase in the reaction conditions, and its contact with the catalyst $[1,18]$. It is demonstrated that titania does not show any activity in this reaction. Moreover, the use of another solvent such as acetonitrile induces the leaching of the metallic species in comparison with n-heptane. For this reason and others like the high power of n-heptane to dissolve molecular oxygen, the use of this alkane as a solvent has been chosen [19].

Figure 5 shows the results of the cyclohexene oxidation by molecular oxygen on different prepared materials. $\mathrm{TiO}_{2}$ does not have any conversion of cyclohexene. In contrary, the metallization of titania enhances its catalytic activity especially in the presence of gold nanoparticles. AuTi has been active since the first time of the reaction and a conversion in the range of $16 \%$ was achieved. FeTi monometallic catalyst does not show any activity in the first time, but after $24 \mathrm{~h}$ it starts the cyclohexene consumption. This result indicates that iron needs more time to react than gold (Figure 5).

Table 2. Product obtained after $24 \mathrm{~h}$ of cyclohexene oxidation by $\mathrm{O}_{2}$

\begin{tabular}{lccccc}
\hline \multicolumn{2}{c}{ Catalysts } & $\mathbf{S}_{\mathbf{A}}(\boldsymbol{\%})$ & $\mathbf{S}_{\text {ENONe }}(\boldsymbol{\%})$ & $\mathbf{S}_{\text {ENOL }}(\boldsymbol{\%})$ & $\mathbf{S}_{\text {EPO }}(\boldsymbol{\%})$ \\
\hline Ti & 41 & 00 & 00 & 00 & 00 \\
AuTi & 52 & 75 & 17 & 08 & 00 \\
FeTi & 50 & 96 & 00 & 00 & 04 \\
AuFeI & 66 & 90 & 07 & 03 & 00 \\
AuFeC & 61 & 81 & 10 & 09 & 00 \\
\hline
\end{tabular}

S: selectivity, A: adipic acid, ENONE: cyclohex-2-enone, ENOL: cyclohex2-enol, EPO: cyclohexane epoxide. Cyclohexene: $4.5 \mathrm{~mL}$, Solvent (nheptane): $75 \mathrm{~mL}$, Oxidant $\left(\mathrm{O}_{2}\right)=6$ bars, mcat $=0.1 \mathrm{~g}$ and $\mathrm{t}=24 \mathrm{~h}$.

In the case of bimetallic catalyst prepared by one-pot (CoDPU), it is clearly detected that the catalyst AuFeC shows the best conversion of cyclohexene in the range of $50 \%$ in the first hours of the reaction and it keeping this activity during $24 \mathrm{~h}$ (Figure 6). Also, it is noted that AuFeI shows an important activity close to $50 \%$ after just $6 \mathrm{~h}$ of contact.

M. Shahabi Nejad et al. [18] were studied the cyclohexene oxidation by $\mathrm{O}_{2}$ using Au-modified-Bentonite $\left(25 \mathrm{~m}^{2} \cdot \mathrm{g}^{-1}\right)$ and $\mathrm{Au}$-modified- $\mathrm{SiO}_{2}\left(378 \mathrm{~m}^{2} . \mathrm{g}^{-1)}\right.$ as catalysts in a free solvent condition and varied the reaction time and oxidant pressure $\left(\mathrm{O}_{2}\right)$. They have selected $8 \mathrm{~h}$ as the good duration for the oxidation reaction over silica-supported catalyst, and $10 \mathrm{~h}$ for Bentonite-supported catalyst. They attributed this difference to the surface area; the catalyst $\mathrm{Au}$-modified- $\mathrm{SiO}_{2}$ that have more surface area and consequently more than 14 probability to react with cyclohexene in a minimal period [18]. Concerning the $\mathrm{O}_{2}$ pressure, they varied it from $8,10,13$ to 15 bars. They evoked that 13 and 8 bars were good pressures for 
Au-modified-SiO 2 and Au-modified-Bentonite, respectively. They also concluded that the surface of the material was the key factor to control the suitable pressure of $\mathrm{O}_{2}$. A maximum of $92 \%$ conversion and $97 \%$ selectivity of 2-cyclohexen-1enone were obtained with the $\mathrm{Au}$-modified- $\mathrm{SiO}_{2}$.

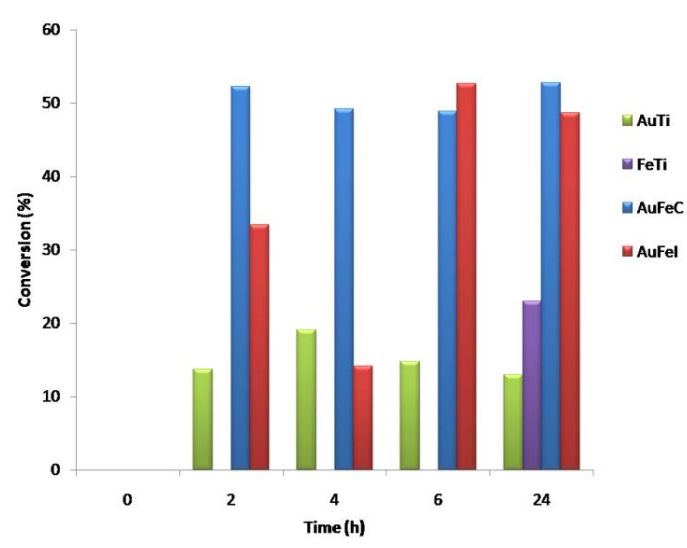

Figure 5. Cyclohexene oxidation on monometallic catalysts

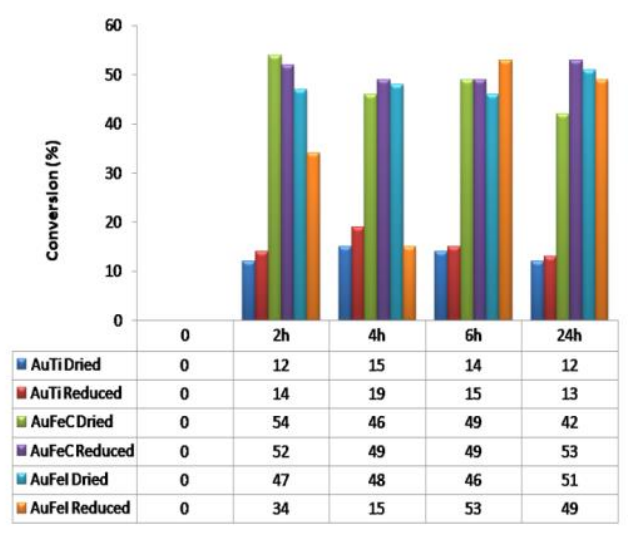

Figure 6. Effect of the annealing treatment on the catalytic activity of metalized Titania

In our case, the best catalytic activity has been achieved just after two hours of the reaction and kept during $24 \mathrm{~h}$. All catalysts have typically the same range of surface. So, our results can be explained by the synergetic effect between $\mathrm{Au}$ and $\mathrm{Fe}$ nanoparticles.

In sum, the bimetallic catalysts show the most important cyclohexene conversion which can reach more than $50 \%$ just after $2 \mathrm{~h}$ of reaction. Thus, the important conversion can be attributed to the presence of the synergetic effect between gold and iron at a very special amount of these metals.

In terms of selectivity, an important selectivity towards the production of adipic acid was achieved, which can reach $90 \%$ with low production of product issue from the allylic oxidation of cyclohexene (cyclohexen-1,2-enone and cyclohexen-1,2enol), is observed in the case of bimetallic catalysts.

These results show that it is possible to have a positive synergetic effect between gold and iron nanoparticles and that the best result was obtained in the case of atomic ratio $\mathrm{Fe} / \mathrm{Au} \approx 0.5$ where the conversion reached more than $50 \%$. Thus, the composition of the catalyst is a crucial factor to determine the selectivity and the production of adipic acid.

Finally, the effect of the annealed treatment of the catalysts on the catalytic activity enhancement is compared. As is shown in Figure 6, all catalysts present typically the same catalytic activity in this reaction, but, at the end of the reaction the color of the as-prepared catalysts are observed to have changed to purple as those reduced. This observation means that the reaction conditions (pressure, temperature and oxygen) are a suitable atmosphere reducing the metallic nanoparticles. Finally, we propose the treatment of the catalysts before reaction to assure their stability.

To explain the formation mechanism of the different products obtained from the present work, different propositions were found in the literature $[3,4,20]$. In the first step of the reaction, oxygen and cyclohexene molecules were adsorbed on the catalyst's surface by interaction with metallic particles. Then, the cyclohexene hydroperoxide was formed by the insertion of $\mathrm{O}-\mathrm{O}$ in the $\mathrm{C}-\mathrm{H}$ bond of cyclohexene in allylic position; where the hydrogen in this position is label. In the second state, this hydroperoxide was transformed into cyclohexen-1,2-ene, or in the presence of a second cyclohexene molecule it can give a mixture of unsaturated alcohol and cyclohexane epoxide (step 3). Cyclohexan-1,2diol was obtained from hydrolysis of cyclohexene epoxide (step 4).

The presence of the continuous flux of molecular oxygen and free sites of catalyst gave, finally, adipic acid after a succession of oxidation and hydrolysis steps (step 5, 6, 7 and 8).
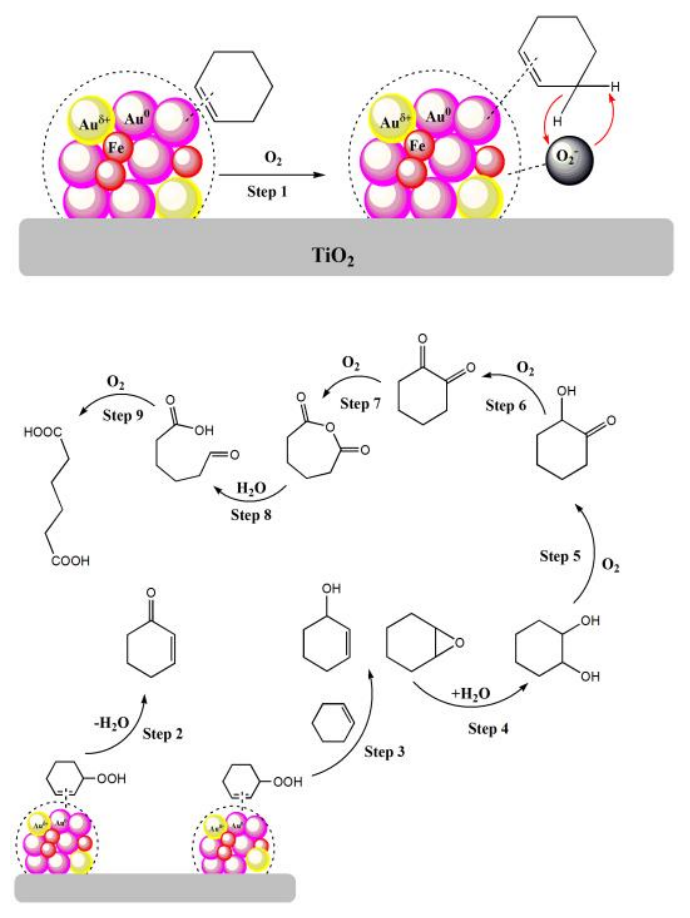

Scheme 2. Proposed reaction path way of cyclohexene oxidation in the presence of molecular oxygen and catalyst

\section{CONCLUSIONS}

The aim of this work was to prepare a bimetallic catalyst based on gold and iron nanoparticles supported on commercial titania (P25). Two different ways were chosen for the preparation of bimetallic catalysts: simultaneous deposition of gold and iron by co-deposition precipitation (Co-DPU) and deposition of gold succeeded by iron impregnation (DPU+IMP). The characterization techniques prove that these two methods led to the preparation of bimetallic catalysts with the same amount of metals, with well distribution and reduced sizes. 
For cyclohexene oxidation by molecular oxygen, an important conversion of cyclohexene $(\approx 50 \%)$ obtained just after $2 \mathrm{~h}$ in the case of AuFeC was observed. In terms of selectivity, all catalysts show an excellent adipic acid production up to $90 \%$. As a result, a green chemistry route was obtained from direct oxidation of cyclohexene to adipic acid using bimetallic catalyst in one-step reaction.

\section{REFERENCES}

[1] Cai, Z.Y., Zhu, M.Q., Chen, J., Shen, Y.Y., Zhao, J., Tang, Y., Chen, X.Z. (2010). Solvent-free oxidation of cyclohexene over catalysts Au/OMS-2 and Au/La-OMS2 with molecular oxygen. Catalysis Communications, 12(3):

197-201. https://doi.org/10.1016/j.catcom.2010.09.014

[2] Weiner, H., Trovarelli, A., Finke, R.G. (2003). Expanded product, plus kinetic and mechanistic, studies of polyoxoanion-based cyclohexene oxidation catalysis: The detection of $\sim 70$ products at higher conversion leading to a simple, product-based test for the presence of olefin autoxidation. Journal of Molecular Catalysis A: Chemical, 191(2): 217-252. https://doi.org/10.1016/S1381-1169(02)00344-8

[3] Nawal, B.R.A., Sumeya, B., Abderrahim, C.B. (2017). Promotional effect of iron on the activity of $\mathrm{TiO}_{2}$ in the production of adipic acid. Annales de Chimie - Science des Matériaux, 41: 173-188. https://doi.org/10.3166/ACSM.41.173-188

[4] Ameur, N., Bachir, R., Bedrane, S., Choukchou-Braham, A. (2017). A green route to produce adipic acid on $\mathrm{TiO}_{2}$ $\mathrm{Fe}_{2} \mathrm{O}_{3}$ nanocomposites. Journal of the Chinese Chemical Society, 64(9): 1096-1103. https://doi.org/10.1002/jccs.201700130

[5] Ameur, N., Berrichi, A., Bedrane, S., Bachir, R. (2014). Preparation and characterization of $\mathrm{Au} / \mathrm{Al}_{2} \mathrm{O}_{3}$ and $\mathrm{Au}$ $\mathrm{Fe} / \mathrm{Al}_{2} \mathrm{O}_{3}$ materials, active and selective catalysts in oxidation of cyclohexene. Advanced Materials Research, 856: 48-52. https://doi.org/10.4028/www.scientific.net/AMR.856.48

[6] Ameur, N., Bedrane, S., Bachir, R., Choukchou-Braham, A. (2013). Influence of nanoparticles oxidation state in gold based catalysts on the product selectivity in liquid phase oxidation of cyclohexene. Journal of Molecular Catalysis A: Chemical, 374-375: 1-6. https://doi.org/10.1016/j.molcata.2013.03.008

[7] Cai, Z.Y., Zhu, M.Q., Dai, H., Liu, Y., Mao, J.X., Chen, X.Z., He, C.H. (2011). Halloysite nanotubes supported gold catalyst for cyclohexene oxidation with molecular oxygen. Advances in Chemical Engineering and Science, 01(01): 15-19. https://doi.org/10.4236/aces.2011.11003

[8] Pestryakov, A.N., Bogdanchikova, N., Simakov, A., Tuzovskaya, I., Jentoft, F., Farias, M., Díaz, A. (2007). Catalytically active gold clusters and nanoparticles for CO oxidation. Surface Science, 601(18): 3792-3795. https://doi.org/10.1016/j.susc.2007.04.012

[9] Zanella, R., Louis, C. (2005). Influence of the conditions of thermal treatments and of storage on the size of the gold particles in $\mathrm{Au} / \mathrm{TiO}_{2}$ samples. Catalysis Today, 107108: 768-777. https://doi.org/10.1016/j.cattod.2005.07.008

[10] Zanella, R., Giorgio, S., Shin, C.H., Henry, C.R., Louis,
C. (2004). Characterization and reactivity in CO oxidation of gold nanoparticles supported on $\mathrm{TiO}_{2}$ prepared by deposition-precipitation with $\mathrm{NaOH}$ and urea. Journal of Catalysis, 222(2): 357-367. https://doi.org/10.1016/j.jcat.2003.11.005

[11] Gluhoi, A.C., Bogdanchikova, N., Nieuwenhuys, B.E. (2005). Alkali (earth)-doped Au/Al2O3 catalysts for the total oxidation of propene. Journal of Catalysis, 232(1): 96-101. https://doi.org/10.1016/j.jcat.2005.02.016

[12] Mohamed, M.B., Volkov, V., Link, S., El-Sayed, M.A. (2000). The 'lightning' gold nanorods: fluorescence enhancement of over a million compared to the gold metal. Chemical Physics Letters, 317(6): 517-523. https://doi.org/10.1016/S0009-2614(99)01414-1

[13] Eustis, S., El-Sayed, M.A. (2006). Why gold nanoparticles are more precious than pretty gold: Noble metal surface plasmon resonance and its enhancement of the radiative and nonradiative properties of nanocrystals of different shapes. Chemical Society Reviews, 35(3): 209-217. https://doi.org/10.1039/B514191E

[14] Yang, J., Zhang, J., Zhu, L., Chen, S., Zhang, Y., Tang, Y., Zhu, Y., Li, Y. (2006). Synthesis of nano titania particles embedded in mesoporous SBA-15: Characterization and photocatalytic activity. Journal of Hazardous Materials, 137(2): 952-958. https://doi.org/10.1016/j.jhazmat.2006.03.017

[15] Pillai, S.C., Periyat, P., George, R., McCormack, D.E., Seery, M.K., Hayden, H., Colreavy, J., Corr, D., Hinder, S.J. (2007). Synthesis of High-Temperature Stable Anatase $\mathrm{TiO}_{2}$ Photocatalyst. The Journal of Physical Chemistry C, 111(4): 1605-1611. https://doi.org/10.1021/jp065933h

[16] Zukal, A., Arean, C.O., Delgado, M.R., Nachtigall, P., Pulido, A., Mayerová, J., Čejka, J. (2011). Combined volumetric, infrared spectroscopic and theoretical investigation of $\mathrm{CO}_{2}$ adsorption on $\mathrm{Na}-\mathrm{A}$ zeolite. Microporous and Mesoporous Materials, 146(1): 97-105. https://doi.org/10.1016/j.micromeso.2011.03.034

[17] Ahmed, M.A., El-Katori, E.E., Gharni, Z.H. (2013). Photocatalytic degradation of methylene blue dye using $\mathrm{Fe}_{2} \mathrm{O}_{3} / \mathrm{TiO}_{2}$ nanoparticles prepared by sol-gel method. Journal of Alloys and Compounds, 553: 19-29. https://doi.org/10.1016/j.jallcom.2012.10.038

[18] nejad, M.S., Ghasemi, G., Martínez-Huerta, M.V., Ghiaci, M. (2015). Synthesis and characterization of $\mathrm{Au}$ nanocatalyst on modifed bentonite and silica and their applications for solvent free oxidation of cyclohexene with molecular oxygen. Journal of Molecular Catalysis A: Chemical, 406: 118-126. https://doi.org/10.1016/j.molcata.2015.05.026

[19] Golovanov, I.B., Zhenodarova, S.M. (2005). Quantitative structure-property relationship: XXIII solubility of oxygen in organic solvents. Russian Journal of General Chemistry, 75(11): 1795-1797. https://doi.org/10.1007/s11176-005-0512-7

[20] Dapurkar, S.E., Kawanami, H., Komura, K., Yokoyama, T., Ikushima, Y. (2008). Solvent-free allylic oxidation of cycloolefins over mesoporous CrMCM-41 molecular sieve catalyst at $1 \mathrm{~atm}$ dioxygen. Applied Catalysis A: General, 346(1): https://doi.org/10.1016/j.apcata.2008.05.01 